\title{
ADMS-Automatic Diabetic Management System
}

\author{
Amala Benny, Neethu Suman
}

\begin{abstract}
Diabetes could be a common chronic disease in mostly all countries worldwide. Monitoring of glucose level of blood is vital to avoid complications of diabetic and damage to organs. The most commonly used method to live glucose level in blood is an invasive method which is painful, expensive and danger in spreading infectious diseases. Over an extended term, the invasive method results in damage of finger tissues. The proposed system works on a diabetes patient, and gives information about patient condition to patient carer or observer. Patient's fingertip is placed between the glucose measuring sensors that measure glucose value through the help of microcontroller. If the glucose level is increased insulin injector will automatically inject the insulin in the body and if it is decreased glucose is injected. Patient's mobile application use to see glucose measurement at each time and also the injected glucose and insulin amount. In critical condition, sms containing vital information and location are sent to doctor or relative's phone.
\end{abstract}

Keywords: Continuous Glucose Monitoring System, Diabetic Management System, Wireless Body Area Network.

\section{INTRODUCTION}

Diabetes is one quite disease of the pancreas, which is liable for producing a hormone called insulin. Diabetes happens when the pancreas gland is no longer able to produce insulin or the body cannot properly utilize the insulin delivered by the pancreas, resulting in the high level of blood glucose in the bloodstream. However, the physical body needs some glucose because it provides the required energy for the body to figure. The high prevalence of diabetes is thanks to unmanaged and uncontrolled diabetes levels among patients. Despite no cure for diabetes has been found so far, the symptoms can be alleviated, and complications can be reduced to a great extent. Majorly there are two types of diabetes namely 1) Type 1 DM 2) Type 2 DM. The failure of the pancreas in the production of enough insulin results in Type 1 DM. In Type1 DM, the pancreatic cells which produce insulin are attacked by the immune system which results decrease in secretion of insulin. Type $2 \mathrm{DM}$ is due to the condition in which the cells fail to respond to insulin. It is determined by increase in resistance of body cells with respect to insulin.

Revised Manuscript Received on May 20, 2020.

* Correspondence Author

Amala Benny, PG Scholar, Department of ECE, Adi Shankara Institute of Engineering and Technology, Ernakulam, India E-mail: amalaann1997@gmail.com

Neethu Suman, Assistant Professor, Department of ECE, Adi Shankara Institute of Engineering and Technology, Ernakulam, India E-mail: neethu.ec@adishankara.ac.in
Type $2 \mathrm{DM}$ is the progression of pre-diabetes and it can be classified as Impaired Glucose Tolerance (IGT) and Impact Fasting Glucose (IFG) [1]. Excess blood glucose decreases the elasticity of blood vessels and causes them to narrow. This can cause a reduced supply of blood and oxygen, increasing the danger of high vital sign and damage to large and little blood vessels. If the blood sugar drops very low (usually below $20 \mathrm{mg} / \mathrm{dL}$ ), the person become confused or drowsy or even lose consciousness and possibly die. Ongoing monitoring of blood glucose (BG) level has become imperative within the management and treatment of diabetes. Patients can perform self-monitoring of blood sugar (SMBG) to regulate their insulin levels, to enhance adherence, and to stay BG levels within a traditional range. Thus, the mortality and associated healthcare complications of diabetes are going to be better controlled. Very often, failure to manage diabetes results into lower quality of life, increased economic burden, and social problems. Consequently, societal costs related to hospitals, readmission rates and hospital visits with cases of hypoglycemia/hyperglycemia can be reduced with continuous monitoring. Therefore, there is an increasingly high need for cost-effective healthcare services that can be provided to everyone, everywhere, and anytime ubiquitously to support and monitor patients to avoid expensive hospital-based care.

The evolution of Pervasive Healthcare Systems (PHSs)[2] is a promising potential for unobtrusive remote health monitoring anywhere and anytime. It empowers the patients with the power to detect their symptoms at an earlier stage and to simply share their medical information with healthcare professionals for further real-time analysis, diagnosis and timely intervention without spatial-temporal restrictions. In case of emergencies, the concerned parties are often alerted through message or email notifications. Consequently, the wide usage and adoption of PHSs can cause better self-disease management, monitoring of patient conditions and significant reduction in healthcare economic burden and hospital visits.

PHSs include WBAN (Wireless Body area network) which is an emerging technology involving the use of wireless communication whereby low-power, intelligent, small-sized, lightweight, and invasive or non-invasive sensors function within the vicinity of the human body to detect the patient's vital signs. WBAN is gaining major interest with the widespread Plethora of obtainable technologies supporting

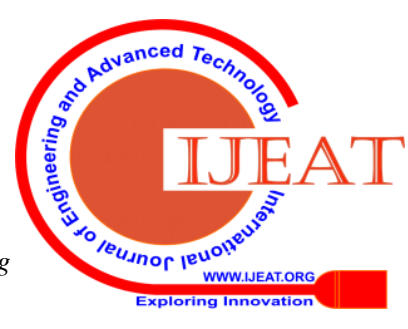




\section{ADMS-Automatic Diabetic Management System}

medical and healthcare applications. Increase in diabetes leading to a worldwide paradigm shift from doctor-centric to patient-centric whereby WBANs have a fundamental role in addressing the multifarious challenges in healthcare. The recent advancements and evolution in WBAN have demonstrated the large potential to enhance the standard of lifetime of diabetic patients. Nevertheless, these WBANs require high level of data reliability and quality to be effective and widely adopted.

Alarming reasons like high societal and economic burden are triggering various research works within the sector of healthcare especially in continuous monitoring of diabetic patients using WBAN. Furthermore, the benefits of the WBAN are beyond argument as they have the potential to reinforce the health conditions and lifelong expectation of diabetic patients.

The remaining sections of this paper are follows: Section II presents the literature survey associated with glucose monitoring systems. Section III provides detailed description of the general ADMS. Section IV presents the performance outcome of the ADMS. Finally, Section V is conclusion of this project.

\section{LITERATURE SURVEY}

\section{A. A1C Test}

The $\mathrm{A} 1 \mathrm{C}$ test is sometimes called the hemoglobin $\mathrm{A} 1 \mathrm{C}$, HbA1c, glycatedhemoglobin, or glycohemoglobin test. Hemoglobin is that part of a red blood corpuscle that carries oxygen to the cells. Glucose attaches to or binds with hemoglobin in your blood cells, and therefore the A1C test is predicated on this attachment of glucose to hemoglobin. A1C test measures the quantity of hemoglobin with attached glucose and reflects your average blood sugar levels over the past 3 months. The A1C test result's reported as a percentage. The higher the share, the upper your blood sugar levels are. A normal A1C level is below 5.7 percent.

\section{B. Traditional system}

The gold standard way for diabetic patients to perform SMBG is through a blood sugar meter, an uncomfortable and slow process. A small blood sample $(<1 \mu \mathrm{L})$ is retrieved by a pricking the finger using a lancet and the sample is transferred immediately to a test strip. The test strip is then put into a blood glucose meter to provide the glucose readings. This method is invasive and painful. It is also inconvenient and causes skin injury since the patients need to draw out their blood several times per day.

\section{Continuous glucose monitoring systems}

Besides the conventional methods, there are other alternative glucose monitoring technologies such as continuous glucose monitoring systems (CGMs), invasive, minimally invasive and non-invasive glucose monitoring systems.[3]

CGMs uses Food and Drug Association (FDA)-approved glucose sensors placed into the human body, which detect the BG levels in the interstitial fluid. CGMs can improve glycaemic control of patients through continuous and automatic monitoring without having to try and do finger pricks. CGMs usually provide recordings of a minimum of 72 $\mathrm{h}$ with the likelihood of obtaining up to 288 BG level readings/day. The CGMs' glucose sensor is implanted right beneath the skin and is connected to a transmitter that continuously sends the info to a receiver. The latter is a small external monitor usually built in to an insulin pump to monitor BG levels and take necessary actions in case of anomalous readings. These devices provide in depth information about glucose such as frequency and duration of hypoglycemia/hyperglycemia on a daily basis.

CGMs' benefits are beyond arguments and have proven to be very effective in providing instantaneous and real-time $\mathrm{BG}$ readings to patients. These information and trends are very helpful to both patients and healthcare professionals to perform analysis, detection and prediction of hypoglycemia/hyperglycaemia. Moreover,CGMs empower patients and provides them insights to proactively manage their diabetes 24/7. Consequently, the glycated hemoglobin (HbAlc) and risk for hypoglycemia/hyperglycemia are revealed to be significantly reduced albeit the patients are on insulin injections or pump therapy.CGMs can notify, educate, encourage, and alert people with diabetes.[4]

Some leading CGM systems on the market that are widely utilized in clinical practice are (1) DexCom G5 from DexCom Inc., (2) MiniMed® 670G from Medtronic Inc., and (3) FreeStyle ${ }^{\circledR}$ Libre Flash from Abbott Diabetes Care.

DexCom G5,DexCom Inc [5]. Recently, DexCom G5, the primary mobile CGMs has been recently approved by FDA in 2016 to be employed by persons 2 years and older. It includes a discrete sensor that's implanted right beneath the abdomen's skin with a 7-day sensor lifetime. The sensor is attached to a transmitter that continuously sends data on to either a handheld receiver or a mobile every 5 min to display the glucose readings through Bluetooth wireless technology.

MiniMed® 670G [6], Medtronic Inc. The Medtronic MiniMed $® 670 \mathrm{G}$ is that the first hybrid closed-loop system system that has been approved by the FDA in 2016 to trace BG levels and automatically adjust the delivery of basal insulin. The system has two main modes, manual and therefore the auto mode. In the "auto mode, "the pump automatically adjusts the basal insulin delivery supported the glucose values obtained every 5 min from the device. In the "manual mode", the basal insulin is delivered at a continuing rate as programmed by the patients. It consists of a "suspend before low" option where the delivery of insulin is temporarily suspended when the $\mathrm{BG}$ value falls to or approaches a preselected low-glucose limit. Then, it automatically restarts the insulin delivery once the BG value increases or is predicted to increase above a pre-selected limit.

FreeStyle ${ }^{\circledR}$ Libre Flash [7]. The Abbott Diabetes Care Free Style Flash is that the first FDA-approved CGMs in 2017 to be employed by diabetic patients of 18 years or older.

It consists of a small subcutaneous sensor wire (Free Style Libre sensor) that is FDA 
approved for 14-day continuous wear. The sensor period is around $12 \mathrm{~h}$ before BG values are displayed. The sensor records the glucose readings every $15 \mathrm{~min}$ and the readings can be scanned within 1s anytime using the Free Style Libre Reader. The reader has an in-built Free Style Precision BG meter that can detect the sensor within a range of $1-4 \mathrm{~cm}$ to retrieve and display the glucose trend arrow and glucose trend graph with a 15 min frequency till $8 \mathrm{~h}$. Although the glucose trends and alerts are displayed on the reader, the system does not include real-time alarms that can be a disadvantage for patients who are hypoglycemia unaware. Moreover, the system is water resistant for up to one meter in water for a maximum of $30 \mathrm{~min}$ and is thus suitable for water sports. One major limitation is that the system does not work with an insulin pump so the patient will have to administer the insulin dosages.

\section{Comparison of CGM system}

All the three CGMs have their benefits and limitations in terms of their features, sensor lifetime, calibration requirements, simple use, and data analysis. In 2016, DexCom G5 mobile CGM did a serious breakthrough where it had been reported to possess adequate accuracy and reliability. It is to be used without adjunctive SMBG in clinical decision-making. Additionally, in 2016, the FDA has approved MiniMed 670G to be used of continuous basal/bolus insulin delivery. FreeStyleLibre system has undergone several clinical trials whereby its overall accuracy have been proved to be similar to those CGM-systems with high accuracy. Hence, there is a very close cut throat selection of the best CGM system and the cost factor also plays a major role in the choice.

Table I: Accuracy comparison of CGMs

\begin{tabular}{|l|l|l|}
\hline \multicolumn{1}{|c|}{$\begin{array}{c}\text { CGM } \\
\text { SYSTEM }\end{array}$} & \multicolumn{1}{|c|}{ MARD } & $\begin{array}{l}\text { CALIBRATION } \\
\text { REQUIREMEN } \\
T\end{array}$ \\
\hline Dexcom G5 & $\begin{array}{l}9 \% \text { Adults } \\
10 \% \text { Pediatrics }\end{array}$ & 2 times/day \\
\hline $\begin{array}{l}\text { Minimed } \\
\text { 670G }\end{array}$ & $\begin{array}{l}9.64 \% \text { Children } \\
10.55 \% \text { Adults }\end{array}$ & $\begin{array}{l}\text { 3-4times/day } \\
1-2 \text { times/day }\end{array}$ \\
\hline $\begin{array}{l}\text { Free style } \\
\text { libre flash }\end{array}$ & $\begin{array}{l}11.4 \% \text { for all } \\
\text { ages }\end{array}$ & $\begin{array}{l}\text { No calibration } \\
\text { required }\end{array}$ \\
\hline
\end{tabular}

\section{E. Non-Invasive Devices for Glucose Monitoring}

The unprecedented advancement in healthcare has led to the event of various wearable and miniaturized sensor technologies to reinforce the patients' quality of life and to stop the danger of complications of diabetes. Different sensors are being developed to live key biomarkers like glucose in human fluid aside from blood.

Emerging non-invasive blood sugar monitoring techniques are currently being developed through the analysis of tear, sweat, saliva, breath and urine. These techniques are highly attractive alternatives to blood measurements. They can play a serious role in blood sugar monitoring by alleviating the pain and discomfort of patients and thus contributing to a better quality of life and reduced healthcare costs.
Table II briefly describes some recent non-invasive devices for glucose monitoring. The target site, technology used, and status of each of the devices are also provided

Table II: Comparison table for non-invasive devices used for glucose monitoring

\begin{tabular}{|c|c|c|c|}
\hline Device & Target & Technology & Status \\
\hline $\begin{array}{l}\text { Glucose Pop } \\
\text { Test[8] }\end{array}$ & Saliva & $\begin{array}{l}\text { Enzymatic } \\
\text { detection of } \\
\text { glucose } \\
\text { levels } \\
\text { in saliva }\end{array}$ & $\begin{array}{l}\text { Available in } \\
\text { US } 2016\end{array}$ \\
\hline $\begin{array}{l}\text { iQuickIt } \\
\text { saliva } \\
\text { analyzer[9] }\end{array}$ & Saliva & $\begin{array}{l}\text { Enzymatic } \\
\text { detection of } \\
\text { glucose } \\
\text { levels } \\
\text { in saliva }\end{array}$ & $\begin{array}{l}\text { Still under } \\
\text { clinical } \\
\text { development }\end{array}$ \\
\hline $\begin{array}{l}\text { Ocular } \\
\text { Glucose } \\
\text { Monitor[10 } \\
\text { ] }\end{array}$ & $\begin{array}{l}\text { Ocular } \\
\text { tears }\end{array}$ & $\begin{array}{l}\text { Surface } \\
\text { Plasmon }\end{array}$ & $\begin{array}{l}\text { Still under } \\
\text { clinical } \\
\text { development }\end{array}$ \\
\hline $\begin{array}{l}\text { Tear } \\
\text { TOUCH } \\
\text { Sensor[11] }\end{array}$ & $\begin{array}{l}\text { Ocular } \\
\text { tears }\end{array}$ & $\begin{array}{l}\text { Enzymatic } \\
\text { detection of } \\
\text { glucose } \\
\text { levels } \\
\text { in tears }\end{array}$ & $\begin{array}{l}\text { Still under } \\
\text { clinical } \\
\text { development }\end{array}$ \\
\hline $\begin{array}{l}\text { Glucos } \\
\text { Alarm[12] }\end{array}$ & Urine & $\begin{array}{l}\text { Uses light } \\
\text { Sensor }\end{array}$ & $\begin{array}{l}\text { Awaiting } \\
\text { FDA } \\
\text { approval } \\
\text { Expects to be } \\
\text { on the US } \\
\text { market in } \\
2017\end{array}$ \\
\hline $\begin{array}{l}\text { Wearable } \\
\text { sweat } \\
\text { monitoring } \\
\text { patch[13] }\end{array}$ & Sweat & $\begin{array}{l}\text { Enzymatic } \\
\text { detection of } \\
\text { glucose } \\
\text { levels in } \\
\text { sweat }\end{array}$ & $\begin{array}{l}\text { Still under } \\
\text { clinical } \\
\text { development }\end{array}$ \\
\hline
\end{tabular}

\section{METHODOLOGY AND SYSTEM ARCHITECTURE}

\section{A. Block diagram of ADMS}

Figure 3.1 shows the block diagram of proposed system. It consists of Sugar level monitoring module, Microcontroller, Injection control module and Alert system. Sugar level module and injection module is connected to microcontroller using wired connection and from controller to alert system by wireless connection. Sugar level monitoring module measures the BG level in the blood and this value is send to microcontroller. Microcontroller compares this value with the predefined BG levels. If the glucose level is increased insulin injector will automatically inject the insulin in the body and if it is decreased glucose is injected. 
ADMS-Automatic Diabetic Management System

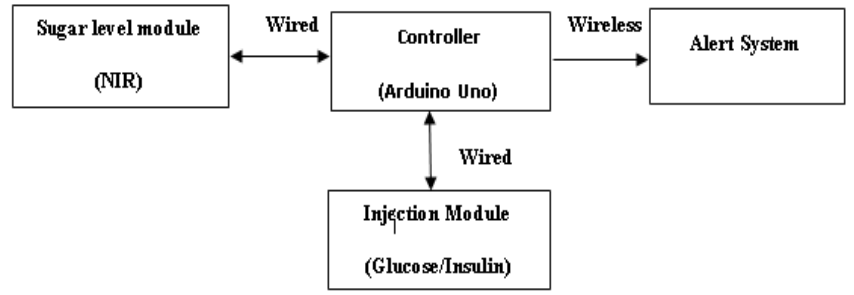

Figure 3.1: Block Diagram of Automatic Diabetic Management System

\section{B. Sugar level monitoring module}

Basic Principle of Glucose level Measurement [14]

When a light ray passes through biological tissues, it's both absorbed and scattered by the tissues. Light scattering occurs in biological tissues thanks to the mismatch between the refraction index of ECF and therefore the membranes of the cells. Variation in BG level affects the intensity of light scattered from the tissue. Beer-Lambert Law plays a significant role in absorbance measurement which states that absorbance of sunshine through any solution is in proportion with the concentration of the solution and thus the length path travelled by the light ray. Light transport theory describes light attenuation as

$$
I=I_{0} \theta^{-\mu} \theta f f^{2}
$$

Where, ' $I$ ' is the reflected light intensity, ' $I_{\square}$ ' is the incident light intensity and $\mathrm{L}$ is the optical path length inside the tissue. Attenuation of light inside the tissue depends on the coefficient known as effective attenuation coefficient $\left(\mu_{\theta / f}\right)$, which is given by

$$
\mu_{\theta f f}=\left[3 \mu_{s}\left(\mu_{s}+\mu_{s}^{\prime}\right)\right] L
$$

The absorption coefficient $\left(\mu_{a}\right)$ is defined as the probability of absorption of photons inside the tissue per unit path length, which is given by

$$
\mu_{a}=2.303 \in \mathrm{C}
$$

' $E$ ' is the molar extinction coefficient, ' $\mathrm{C}$ ' is the tissue chromophore concentration and the reduced scattering coefficient $\left(\mu_{s}^{\prime}\right)$ is given by equation

$$
\mu_{s}^{\prime}=\mu_{s}(1-g)
$$

Where ' $\mathrm{g}$ ' is anisotropy and ' $\mu_{s}$ ' is scattering coefficient. ' $\mathrm{a}$ ' depends on the glucose concentration in blood. Thus with the increase in blood glucose concentration, the scattering property of blood decreases.

\section{Block Diagram of Sugar level monitoring module}

Figure 3.2 shows the block Diagram of Sugar level monitoring module. Sensing unit consists of NIR emitter $(1450 \mathrm{~nm})$ and NIR receiver (photo detector) positioned on either side of the fingertip. Transmitted signal is received by the photo detector and it is fed to a amplifier and filter. After noise filtration and amplification, these wave signals are converted into a suitable voltage value and the microcontroller converts these voltage values to an equivalent glucose value using the equation (5)

$$
\mathrm{Y}=1398.7 * \mathrm{X}-2361.2[15]
$$

Where $\mathrm{X}$ is the voltage and $\mathrm{Y}$ is the corresponding glucose value. This glucose value is send to coordinator through Bluetooth module.

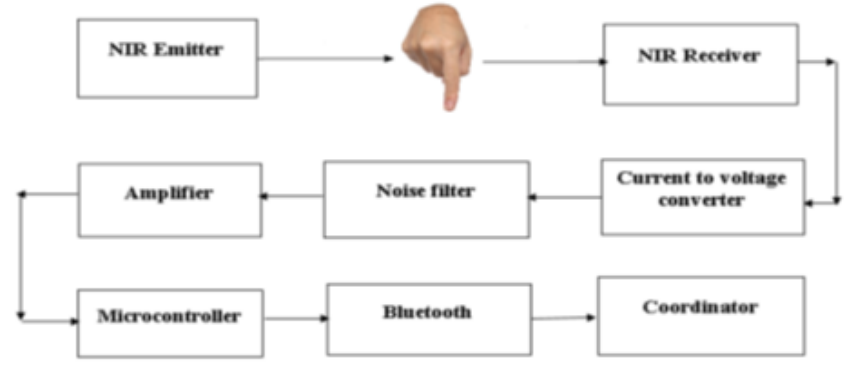

Figure 3.2: Block Diagram of Sugar level monitoring module

\section{Injection control module}

\section{Block diagram of injection control module}

According to the glucose level in the microcontroller, if it's high, insulin injector will automatically inject the insulin in the body based on the criteria by using an insulin injection pump. If it is low, glucose is injected based on the criteria by glucose injection pump. Data was send to the microcontroller and it was send to the coordinator through Bluetooth module. Figure 3.3 shows the block Diagram of Injection Control module.

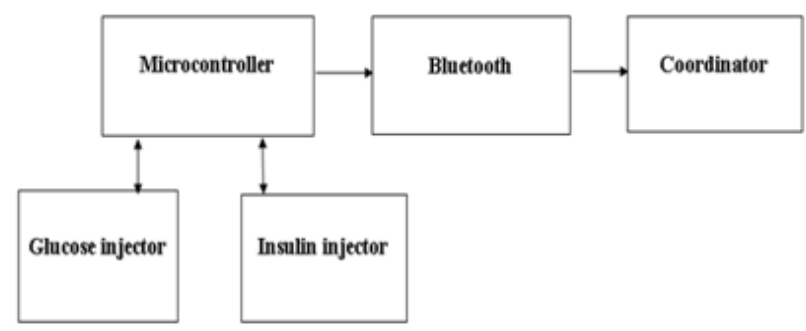

Figure 3.3: Block Diagram of Injection Control module

\section{Flow chart of sugar level and injection control}

Figure 3.4 shows the flow chart of sugar level and injection control. Microcontroller reads the glucose value from the sensor and microcontroller checks this glucose value with BG levels that is predefined programmed in the microcontroller. If it is high, insulin injector will automatically inject the insulin in the body using an insulin injection pump based on the insulin injection criteria shown in the figure 3.5 and again read and checks the glucose value after 15 minutes. If it is normal, the sensor units take the reading of glucose level after one hour.

If the BG level is low, glucose injector will automatically inject the glucose in the body based on 15-15 rule by using a glucose injection pump Low blood sugar (also known as 
hypoglycemia) is when your blood sugar levels have fallen low enough that you need to take action to bring them back to your target range. This is usually when your blood sugar is less than $70 \mathrm{mg} / \mathrm{dL}$. The $15-15$ rule-has 15 grams of carbohydrate to raise your blood sugar and check it after 15 minutes and continue the process till the glucose level is normal.

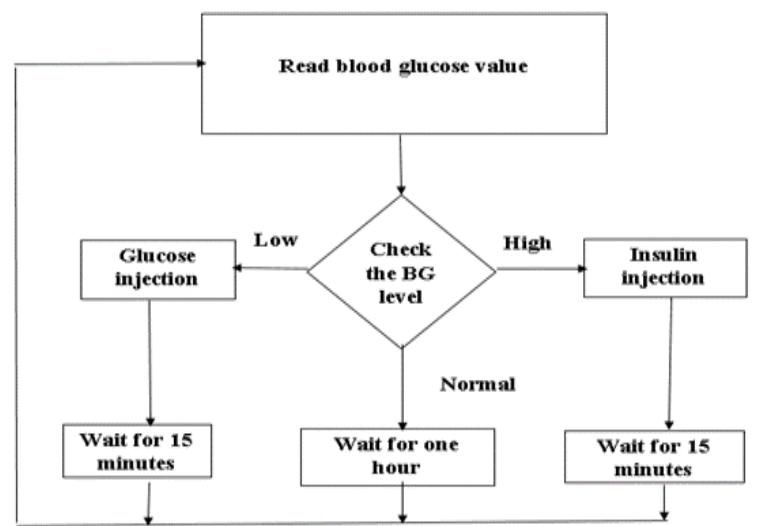

Figure 3.4: Flow chart of sugar level and injection control

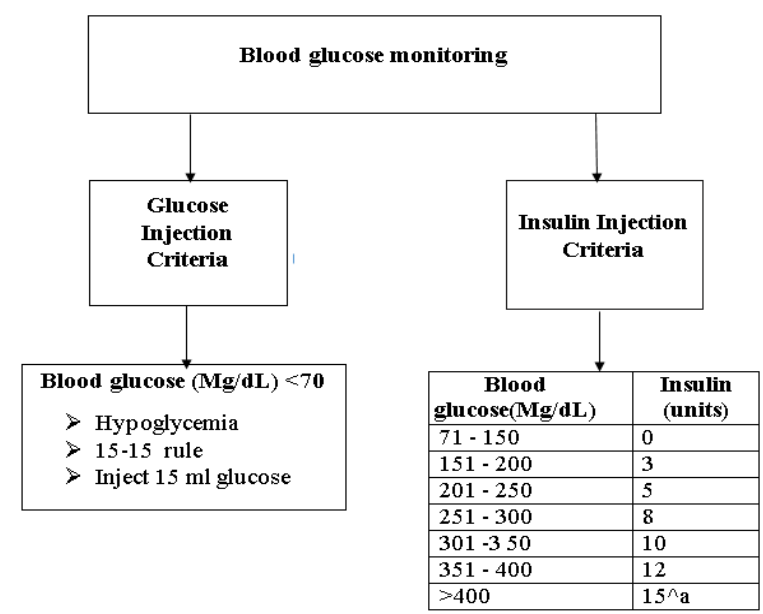

Figure 3.5: Glucose/Injection criteria

D. Alert system

Block diagram of alert system

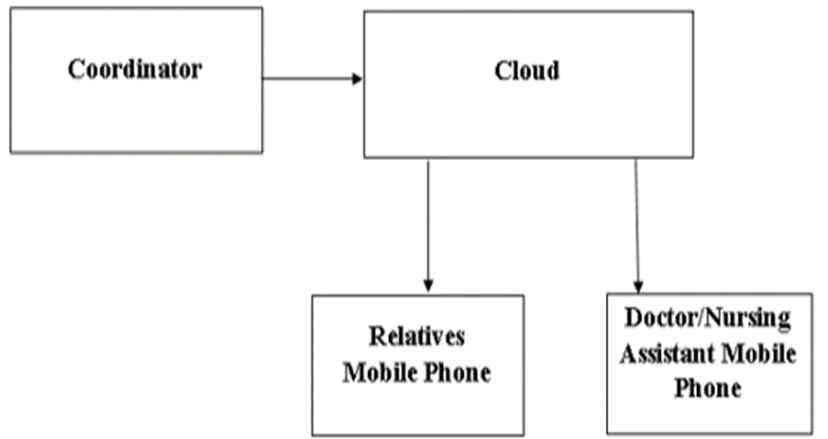

Figure3.6: Block Diagram of Alert System

Figure 3.6 shows the Block Diagram of Alert System.BG levels and the amount of glucose/insulin injected at each time interval is send to the cloud from coordinator through Wireless communication. Android application is created on the mobile phones. If the BG level is very high/very low an alert given to the doctors.

\section{Flow chart of Alert System}

Figure 3.7 shows the flow chart of Alert System. Microcontroller reads the glucose value from the sensor and microcontroller checks this glucose value with BG levels that is predefined programmed in the microcontroller. If it is very high/very low, an alert is given to the doctor and patients relatives. If it is medium high/medium low, waiting period is reduced in to 5 minutes and a first level alert is given to the patient. If it is normal, the sensor units take the reading of glucose level after normal period.

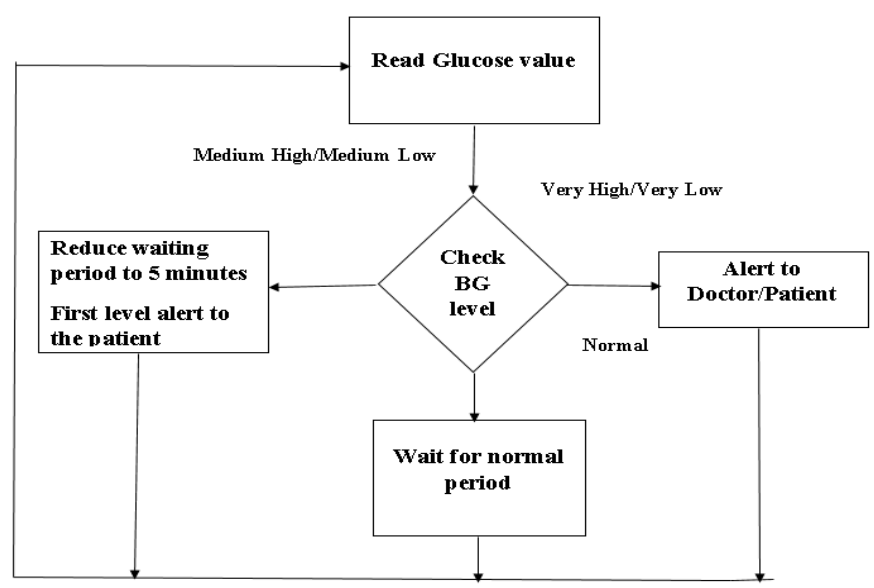

Figure 3.7: Flow chart of Alert System

\section{RESULT AND DISCUSSION}

\section{A. Simulation Circuit}

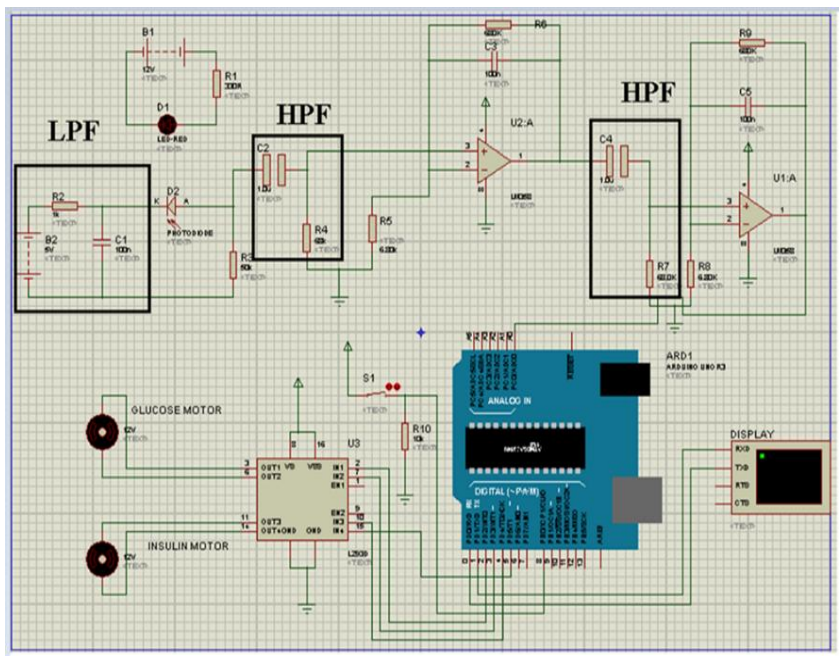

Figure 4.1: Simulation circuit

Proteus is employed as simulation tool. Proteus is a software containing schematic, simulation also as PCB designing. ISIS is that the software used to draw schematics and simulate the circuits in real time. The simulation allows human to access during run time and thus providing real time simulation. ARES is employed for PCB designing. it's the feature of viewing

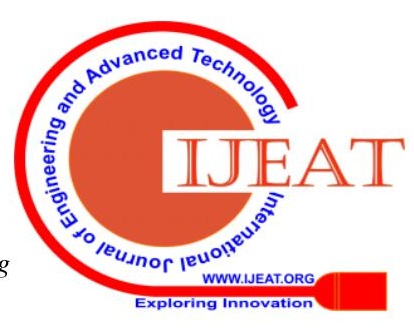




\section{ADMS-Automatic Diabetic Management System}

output in $3 \mathrm{D}$ view of the designed $\mathrm{PCB}$ in conjunction with components. The designer can also develop 2D drawings for the merchandise.

GaAIAs-LED (950nm) is employed as IR light transmitter and photodiode having spectral range of sensitivity- $750 \mathrm{~nm}$ to $1120 \mathrm{~nm}$ wavelength is employed to detect attenuated light .Figure 4.1 shows measuring setup. It contains two different part, constant current IR emitter circuit having the capabilities of $100 \mathrm{~mA}$ current and a couple of $.5 \mathrm{v}$ voltage carrying capacities and signal conditioning circuit. The electrical current obtained from the photo detector is converted into the voltage by placing the load resistance $\mathrm{R} 4=$ $50 \mathrm{k} \Omega$ at the anode side of photodiode. At the output of photodiode signal is corrupted thanks to external and other factors.

To reduce the noise, low pass filter is used to remove unwanted noise from signal. The cut-off frequency of low pass filter is designed as $1.59 \mathrm{kHz}$ respectively.

Cut off frequency of LPF $=1 /(2 \pi \mathrm{R} 1 \mathrm{C} 1)=1 /[2 \pi(1 * 103)$

$(100 * 10-9)]=1.59 \mathrm{kHz}$

Signal conditioning stage consist of two stage high pass filter and an integration plus opamp circuit. Integrator is used to average the voltages and opamp is used to amplify the signal. High pass filter is used to remove noise that is generated by converting AC voltage to DC voltage.

Cut off frequency of HPF $=1 /(2 \pi \mathrm{R} 2 \mathrm{C} 2)=1 /[2 \pi(68 * 103)$

$(1 * 10-6)]=2.34 \mathrm{~Hz}$

Voltage gain $=1+(\mathrm{Rf} / \mathrm{Rin})=1+[(680 * 103) /(68 * 103)]=$ 101

The amplified output voltage is connected to analog pin A0 of Arduino due microcontroller for converting the analog signal into digital values. This digital value corresponds to the glucose level. From this digital value, the actual glucose level is determined using equation (5)

Microcontroller checks this glucose value with BG levels that is predefined programmed in the microcontroller and the glucose motor or insulin motor rotate accordingly and the resulting output was shown in the figure 4.2.Based on the glucose value, insulin injection motor rotation is delay is varied. So that the corresponding amount of insulin is injected. When your blood sugar is less than $70 \mathrm{mg} / \mathrm{dL}$, glucose motor will rotated and the corresponding amount of glucose is injected.

\section{CONCLUSION}

The IoT-based non-invasive method using Near-Infrared (NIR) is becoming a really useful option for constant glucose monitoring. As it isn't painful and there's no risk for infection unlike the normal invasive methods, more people are willing to utilize the framework. IoT has been an integral part for variety of various sectors, starting from health care to putting together smart homes. This proposed work can act as a multidimensional health monitoring system because it's capable of blending the monitoring functionality with feature like notifying relevant information to the patient and the observer. The constant remote collection of the patient's glucose readings also will help any doctor to require a choice supported the patient's health, if the patient or the observer decides to debate the obtained information with the doctor.

Study was conducted on the body area networks in diabetic monitoring, existing glucose monitoring systems and Non-invasive devices for glucose monitoring Designed a system to monitor blood glucose level by using Near-Infrared (NIR) light source, which is of $940 \mathrm{~nm}$ wavelength. The intensity of light passed through the finger is used to calculate the blood sugar level. Photodiode having spectral range of sensitivity- $750 \mathrm{~nm}$ to $1120 \mathrm{~nm}$ wavelength is used to detect attenuated light and it is fed to an amplifier and filter. After noise filtration and amplification, these wave signals are converted into a suitable voltage value and the microcontroller converts this voltage value to an equivalent glucose value. If the glucose level is increased insulin injector will automatically inject the insulin in the body and if it is decreased glucose is injected. . Simulation was done and the output was obtained.

\section{REFERENCES}

[1] Ganjar Alfian, Muhammad Syafrudin, Muhammad Fazal Ijaz,M. Alex Syaekhoni, Norma Latif Fitriyani and Jongtae Rhee, A Personalized Healthcare Monitoring System for Diabetic Patients by Utilizing BLE-Based Sensors and Real-Time Data Processing, 2018 Jul; 18(7): 2183. Published online 2018 Jul 6. doi:10.3390/s18072183

[2] A. Dearden, P. Wright, S. Bowen, F. Rahman, M. Cobb, D. Wolstenholme, Pervasive healthcare in lived experience: thinking beyond the home, in Procceedings of the 4th International ICST Conference on Pervasive Computer Technology and Healthcare, (2010), pp. 1-4H.

[3] Lee, K. Park, B. Lee, Issues in data fusion for healthcare monitoring in Issues in Data Fusion for Healthcare Monitoring, no. Jan 2008 (2013)

[4] C. Chen, X. Zhao, Z. Li, Z. Zhu, S. Qian, A.J. Flewitt, Current and emerging technology for continuous glucose monitoring. Sensors 17(1), 182 (2017)

[5] Dexcom Inc., Dexcom and Insulin Pumps. [Online].https://www.dexcom.com/insulinpumps. Accessed 27 Dec 2017

[6] Minimed 670G from Medtronic Inc https://www.medtronicdiabetes.com/products/mini med670ginsulin-pump-system.

[7] FreestyleLibre Flash from Abbott Diabetes Care https://www.freestylelibre.us/index.html.

[8] Pop Test LLC, Glucose Pop TEST. [Online]. 
http://www.diabetespoptest.com/. Accessed 30 Dec 2017.

[9] LLC Quick, IQuickIt Saliva Analyzer (LLC Quick, Farmington, CT).

[10] Light Touch Medical Inc., Ocular Glucose Monitor. [Online]. Available: http://tearglucose.com/. Accessed 30 Dec 2017

[11] J.T. LaBelle, Tear TOUCH Glucose Sensing. [Online]. http://labellelab.asu.edu/research/touch/. Accessed 30 Dec 2017

[12] C. Bernal, GlucosAlarm. [Online]. http://www.glucosalarm.com/. Accessed 30 Dec 2018

[13] H. Lee, C. Song, Y.S. Hong, M.S. Kim, H.R. Cho, T. Kang, K. Shin, S.H. Choi, T. Hyeon,D.-H. Kim, Wearable/disposable sweat-based glucose monitoring device with multistage transdermal drug delivery module. Sci. Adv. 3(3), e1601314 (2017)

[14] Chandrakant D. Bobade, Dr. Mahadev S. Patil, "Non-Invasive Monitoring of Glucose Level in Blood using Near-Infrared Spectroscopy" International Journal of Recent Trends in Engineering \& Research (IJRTER), Volume 02, Issue 06; June - 2016 [ISSN: 2455-1457

[15] Md. Mahbub Alam, Swapnil Saha, Proshib Saha, Fernaz Narin Nur,Nazmun Nessa Moon, Asif Karim and Sami Azam "D-CARE: A Non-invasive Glucose Measuring Technique for Monitoring Diabetes Patients, Proceedings of International Joint Conference on Computational Intelligence Pp. 443-453.

\section{AUTHORS PROFILE}

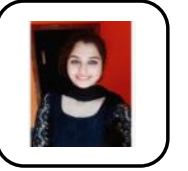

Amala Benny is currently pursing MTech in Communication Engineering from Adi Shankara Institute of Engineering and Technology, Ernakulam, India. She completed her BTech in Electronics and Communication Engineering from Indira Gandhi Institute of Engineering and Technology, Nellikuzhi, Kothamangalam, Kerala.

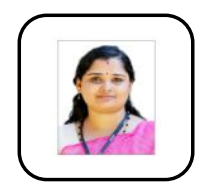

Neethu Suman, is currently working as Assistant Professor at Adi Shankara Institute of Engineering and Technology, Ernakulam, India and doing $\mathrm{PhD}$ in wireless communication under APJ Abdul Kalam Technological University, Kerala, India. She completed her M.Tech in Embedded Systems from Amrita VishwaVidyapeetham University and B.Tech in Electronics and Communication Engineering from M G University. She is an associate member of Institution of Engineers (India). 